Aloman 2019, 37(1), 9-10

Revista de Psicologia, Ciències de l'Eduació i de l'Esport

ISSN: 1138-3194

(C)Facultat de Psicologia, Ciències de l'Educació i de l'Esport Blanquerna

Universitat Ramon Llull

\title{
The Role of Traditions in Psychology (and Other Sciences). Comments on Research traditions in social sciences and their methodological rationales
}

\section{Reply to Gallifa (2018)}

Francesc Salvador-Beltran

Institut de Neurociències, Universitat de Barcelona

What's in a name? That which we call a rose By any other name would smell as sweet;

W. Shakespeare Romeo and Juliet, Act 2, Scene 2

$\underline{T}$ he objective of the text Research traditions in social sciences and their methodological rationales is to clarify and systematise. Order is always welcome - in the academic world and elsewhere. As is well known, and as Groos and Levitt (1994) state, confusion is the foundation of mystification, false theories and superstitions; indeed, it is the basis on which criteria grounded in scientific proof are replaced by ideological criteria. We should therefore welcome the text, which more than achieves these goals of order and clarity. Nevertheless, I would like to add some comments, although I am aware that some of them may open up topics for the sort of debate that would involve writing a much longer review and going beyond the aim of these few lines.

The first thing that strikes the reader is the asymmetry in the amount of space dedicated to the description of each of the traditions covered. In Section 3.1. on Logic empirical science, the text dedicates two short paragraphs to this tradition, while it dedicates between two and four-and-ahalf pages to the other traditions. I do not believe that the authors consider this tradition to be less important or more marginal than the other traditions; rather, I think (out of my own speculation, of course) that they have done so because it is a tradition that is well known to all their potential readers and therefore does not require detailed discussion. Nothing could be further from the truth. It is probably the tradition that gives rise to the most mistakes and misunderstandings, not just among the general public, but even in parts of academia (see the chapter entitled Beliefs and Misunderstandings About Science and Research in Salvador, 2018).

A second comment I would like to make is that, while the title indicates that the content of the text is aimed at the social sciences, the text later states that the discussion of the influence of each tradition will focus particularly on research in psychology and education. Leaving aside the unfortunate division between the social sciences and the natural sciences, which is no less unfortunate for its large following (because it separates nature and society into two different worlds, thus creating an unbearable kind of schizophrenia of knowledge), we find it hard to accept that everything set out in the text can be applied to psychology (understood as the study of behavior in the broadest sense of the term). Without wishing to minimize the influence of some of the traditions described (which are alive and well) on psychology, the option with the largest following (and by a wide margin) in the academic and professional worlds is clear. Examining the progress made in the past 20 years (to use the symbolic date of the turn of the millennium) is sufficient to see which tradition has produced the most important discoveries in recent times. I have very little knowledge of the situation in education and the other social sciences and cannot therefore offer an opinion, but psychology has clearly moved in a specific direction. Or, what amounts to the same thing, not 
all traditions (not even remotely) have the same influence on shaping knowledge in psychology, though the text seems to suggest that they do. Perhaps this is aided by the fact that psychology, or a large part of it, is not fully situated within the conceptual framework of the so-called social sciences (and although, as I have made clear in my earlier comment, I am not in favor of this separation, it is clear that a large part of psychology currently sits within the conceptual framework of the natural sciences).

I have one last comment to make in line with the points in the previous paragraph. The extensive use (and abuse) of the word science often leads to misunderstandings. Science is the knowledge obtained through a specific process (known as the scientific method), which also gives rise to applications and social usage with ethical implications. If we like, we can also call other ways of knowing science, but, as we well know, simply to call them that does not make it so. The commercial success of some science writers, whether out of ignorance or willful deception for their benefit, in presenting science as a guarantee of certain and infallible knowledge (one of the misunderstandings about science mentioned above) has meant that if something does not bear the science label, it is viewed with mistrust in academic and professional spheres, as well as by the general public. This means that anyone can use the label, regardless of whether what they do is strictly science. Perhaps we should start putting things in their place and attributing to each thing the value it has in its context. Each way of knowing has its own value, and it is by this value that we must judge it (indeed, this is more or less what Toulmin [1985] says). So let's give each tradition the (greater or lesser) value it deserves and avoid confusion that generates misunderstandings and often leads to pointless, unproductive arguments.

\section{References}

Gallifa, J. (2028). Research traditions in social sciences and their methodological rationales. Aloma. Revista de Psicologia, Ciències de l'Educació i de l’Esport, 36(2), 9-20.

Groos, P.R. \& Levitt, N. (1994). Higher superstition: The academic left and its quarrels with science. Baltimore: Johns Hopkins University Press.

Salvador, F. (2018). Fonaments de la recerca [Essentials of research]. Barcelona: Edicions de la Universitat Oberta de Catalunya. (2nd edition, revised)

Toulmin, S.E. (1985). The return to cosmology: Postmodern science and the theology of nature. University of California Press. 